\title{
PELAKSANAAN PEMBELAJARAN PENDIDIKAN AGAMA ISLAM OLEH GURU SEKOLAH DASAR PADA GUGUS I LUBUK SIKARAH KOTA SOLOK
}

\author{
Yulmida, AM \\ Pengawas Pendidikan Agama Islam Sekolah Dasarpada \\ Dinas Pendidikan Kota Solok
}

\begin{abstract}
Implementation of Islamic Education Teaching in Primary School Cluster I Lubuk Sikarah Solok. Thesis Magister Program of Management of Islamic Education at Post Graduate Program State College of Islamic Studies (STAIN) Batusangkar, 2014. Cluster I Lubuk Sikarah Solok City is one of the existing Primary School Cluster with a focus to create the best performing students, berbudii noble character, morality based on religious values and customs with the steps instill a sense of faith, morality, and religion God Almighty, improve discipline each school community, improving the professionalism of teachers, educators complementary infrastructure, involving the whole element involved in education to participate actively in order to achieve educational goals.

This study aims to describe the habits of Islamic religious education teachers in preparing lesson plans, habits Islamic religious education teachers in the implementation of learning, habits of Islamic religious education teachers in the evaluation of learning outcomes. This study is an ethnographic research design that uses a qualitative approach with descriptive method of analysis. Data was collected by (1) observation; (2) interview; (3) documentation. Key informants collected by sampling jugmen while additional informants by means of snowball sampling.
\end{abstract}

The results of this study are: (1) Islamic religious education teachers have been professional in preparing lesson plans, (2) Islamic religious education teacher has been a professional in the implementation of learning, (3) Islamic religious education teacher has been a professional in the evaluation of learning outcomes.

Kata Kunci: Pembelajaran, Pendidikan Agama Islam, guru

\section{PENDAHULUAN}

Kemajuan suatu bangsa dapat dilihat dari seberapa maju pendidikan yang telah dicapai, karena pendidikan memberikan kontribusi yang besar bagi bangsa terkait dengan perannya sebagai wahana membentuk karakter bangsa. Dalam Undang-undang Sisdiknas No. 20 tahun 2003 pasal 1 disebutkan pengertian pendidikan yaitu: "Pendidikan adalah usaha sadar dan terencana untuk mewujudkan suasana belajar dan proses pembelajaran agar 
peserta didik secara aktif mengembangkan potensi dirinyauntuk memiliki kekuatan spiritual keagamaan, pengendalian diri, kepribadian, kecerdasan, akhlak mulia, serta keterampilan yang diperlukan dirinya, masyarakat, bangsa, dan negara".

Masih ada silabus dan RPP sebagai bagian dari kurikulum disusun dengan cara menyalin dari pihak lain, misalnya internet, sehingga kurikulum bukan kreatifitas guru untuk memberikan proses pembelajaran yang terbaik kepada siswa, tetapi sebagai tertib administrasi semata. Masih banyak guru PAI yang hanya menyalin silabus yang dibuat oleh BNSP ataupun menyalin RPP yang dibuat oleh Tim Pengembang Kurikulum tanpa mengembangkan sesuai dengan kebutuhan dan kondisi sekolahnya. Guruguru yang melakukan hal tersebut adalah mereka yang tidak mau bersusah payah untuk mengembangkan dirinya (Nunu Ahmad An-Nahidl.,dkk, 2010:26) Pembelajaran cenderung lebih mengedepankan aspek kognitif yang cenderung mengajak siswa untuk menghafal dan mengerjakan soal tanpa mampu berfikir kreatif dan mengesampingkan aspek afektif dan psikomotorik. (Muhaimin, 2006: 70)

Pembelajaran lebih banyak menggunakan metode yang monton seperti metode ceramah tanpa adanya penggunaan media pembelajaran dan PAI diajarkan terbatas pada teori-teori saja dan tidak dikaitan dengan konteks kekinian, akibatnya menimbulkan kebosanan dan kurang menarik bagi siswa. Di samping itu kebanyakan guru mata pendidikan agama Islam pada Gugus I Lubuk Sikarah Kota
Solok sudah mendekati usia pensiun, sehingga kesehatan dan kemampuan mengajarnya sudah menurun. Guru pendidikan agama Islam belum termotivasi untuk mengikuti kualifikasi akademik sesuai dengan bidang tugas yang diembannya.

Dari latar belakang di atas, maka dapat menetapkan fokus masalah yang akan dibahas yaitu Pelaksanaan Pendidikan Agama Islam oleh Guru Sekolah Dasar di Gugus I Lubuk Sikarah Kota Solok, dan selanjutnya dijabarkan dalam sub fokus penelitian sebagai berikut :

1. Bagaimana guru pendidikan agama Islam menyusun rencana pembelajaran

2. Bagaimana guru pendidikan agama Islam melaksanakan pembelajaran

3. Bagaimana guru pendidikan agama Islam mengevaluasi hasil belajar

Sedangkan rumusan masalah dalam penelitian ini adalah bagaimana Pelaksanaan Pendidikan Agama Islam oleh Guru Sekolah Dasar di Gugus I Lubuk Sikarah Kota Solok. Penelitian ini bertujuan untuk mendeskripsikan tentang kebiasaan guru pendidikan agama Islam dalam menyusun rencana pembelajaran, pelaksanaan pembelajaran dan evaluasi hasil belajar.

Penelitian ini tergolong pada penelitian kualitatif yaitu penelitian yang bermaksud memahami fenomena apa yang terjadi atau dialami oleh subjek penelitian dengan suatu konteks khusus yang alamiah dengan jenis penelitian etnografi.

Prosedur analisis data yang digunakan dalam penelitian ini adalah analysis interactive model yang membagi kegiatan analisis menjadi 
empat bagian, yaitu pengumpulan data, reduksi data, penyajian data, dan penarikan kesimpulan atau verifikasi data.

Teknik pengumpulan data dilakukan dengan mengadakan observasi dan wawancara dengan informan penelitian, serta menelaah dokumentasi yang berkaitan dengan tujuan penelitian ini.

\section{PEMBAHASAN}

\section{Landasan Teoritis}

Kata profesional berasal dari profesi yang artinya mampu atau ahli dalam suatu bentuk pekerjaan (Ramayulis, 2003:27. Menuntut adanya keterampilan yang berdasarkan konsep dan teori ilmu pengetahuan yang mendalam.

Jika disandangkan kata profesional kepada guru, maka guru profesional adalah guru yang memiliki kompotensi tertentu sesuai dengan persaratan yang dituntut oleh profesi keguruan" (Danim, 1994:53).

Guru profesional adalah guru yang senantiasa menguasai bahan atau materi pelajaran yang akan diajarkan dalam interaksi belajar mengajar, serta senantiasa mengembangkan kemampuannya secara berkelanjutan, baik dalam segi ilmu yang dimilikinya maupun pengalamannya.

Proses interaksi belajar mengajar merupakan suatu proses yang mengandung serangkaian perbuatan guru dan siswa atas timbal balik yang langsung dalam situasi pendidikan untuk mencapai tujuan tertentu. Interaksi guru dengan siswa bukan hanya dalam penguasaan bahan ajaran, tetapi juga dalam penerimaan nilai-nilai, pengembangan sikap serta mengatasi kesulitaan-kesulitan yang dihadapi oleh siswa. Dengan demikian di dalam interaksi belajar mengajar dalam rangka menimbulkan motivasi belajar siswa, guru bukan hanya saja sebagai pelatih dan pengajar tetapi juaga sebagai pendidik dan pembimbing.

\section{a. Manajemen Pendidikan Islam}

Secara etimologis kata manajemen berasal dari kata managio berarti pengurusan atau managiare yaitu melatih dalam mengatur langkah-langkah, atau dapat berarti bahwa manajemen sebagai ilmu, kiat dan profesi. Jad kata manajemen secara etimologis berarti mengelola, memeriksa atau mengawasi dan mengurus.

Hasan Zaini mengutur pendapat Yunus mengemukakan bahwa secara terminologi Islami yang secara khusus menyebutkan istilah manajemen belum ada yang popular. Namun bila didekati dari istilah bahasa Arab dapat dikemukakan bahwa kata yudabbiru dapat diartikan mengarahkan, mengelola, melaksanakan, menjalankan, mengatur atau mengurusi. Asal katanya adalah dari dabbara yang artinya mengatur dan mudabbir artinya orang yang pandai mengatur atau pengatur mudabbar yang diatur. (Hasan Zaini,2013:5)

\section{b. Fungsi-fungsi Manajemen Pendidikan Islam}
1) Fungsi Perencanaan (Planning)
Perencanaan adalah sebuah proses perdana ketika hendak melakukan pekerjaan baik dalam bentuk pemikiran maupun kerangka kerja agar tujuan yang hendak dicapai mendapatkan hasil 
yang optimal. Demikian pula halnya dalam pendidikan Islam perencanaan harus dijadikan langkah pertama yang benar-benar diperhatikan oleh para manajer dan para pengelola pendidikan Islam. Sebab perencanaan merupakan bagian penting dari sebuah kesuksesan, kesalahan dalam menentukan perencanaan pendidikan Islam akan berakibat sangat fatal bagi keberlangsungan pendidikan Islam. Bahkan Allah SWT., memberikan arahan kepada setiap orang yang beriman untuk mendesain sebuah rencana apa yang akan dilakukan dikemudian hari, sebagaimana Firman-Nya dalam Al Qur'an Surat Al Hasyr : 18 yang berbunyi:

\section{Hai orang-orang yang beriman, bertakwalah kepada Allah dan hendaklah Setiap diri memperhatikan apa yang telah diperbuatnya untuk hari esok (akhirat); dan bertakwalah kepada Allah, Sesungguhnya Allah Maha mengetahui apa yang kamu kerjakan.}

Ketika menyusun sebuah perencanaan dalam pendidikan Islam tidaklah dilakukan hanya untuk mencapai tujuan dunia semata, tapi harus jauh lebih dari itu melampaui batas-batas target kehidupan duniawi. Arah perencanaan itu juga untuk mencapai target kebahagiaan akhirat, sehingga kedua-duanya bisa dicapai secara seimbang.

2) Fungsi Pengorganisasian (organizing) Ajaran Islam senantiasa mendorong para umatnya untuk melakukan segala sesuatu secara terorganisir dengan rapi, sebab bisa jadi suatu kebenaran yang tidak terorganisir dengan rapi akan dengan mudah bisa diluluhlantakan oleh kebathilan yang tersusun rapi.

Pengorganisasian dalam pendidikan Islam adalah proses penentuan struktur, aktivitas, interakasi, koordinasi, desain struktur, wewenang, tugas secara transparan, dan jelas. Dalam lembaga pendidikan Islam, baik yang bersifat individual, kelompok, maupun kelembagaan. (Ramayulis, 2012: 272)

Sebuah organisasi dalam manajemen pendidikan Islam akan dapat berjalan dengan lancar dan sesuai dengan tujuan jika konsisten dengan prinsipprinsip yang mendesain perjalanan organisasi yaitu Kebebasan, keadilan, dan musyawarah. Jika kesemua prinsip ini dapat diaplikasikan secara konsisten dalam proses pengelolaan lembaga pendidikan Islam akan sangat membantu bagi para manajer pendidikan Islam.

3) Fungsi Pengarahan (directing) Fungsi pengarahan dalam manajemen pendidikan Islam adalah proses bimbingan yang didasari prinsip-prinsip religius kepada rekan kerja, sehingga orang tersebut mau melaksanakan tugasnya dengan sungguh- sungguh dan bersemangat disertai keikhlasan yang sangat mendalam. 
4) Fungsi Pengawasan (Controlling)

Pengawasan adalah keseluruhan upaya pengamatan pelaksanaan kegiatan operasional guna menjamin bahwa kegiatan tersebut sesuai dengan rencana yang telah ditetapkan sebelumnya. Bahkan Didin dan Hendri menyatakan bahwa dalam pandangan Islam pengawasan dilakukan untuk meluruskan yang tidak lurus, mengoreksi yang salah dan membenarkan yang hak. (Didin Hafidudin dan Hendri Tanjung, 2003:156)

\section{c. Guru}

1) Pengertian Guru

Pengertian guru adalah pendidik profesional, karenanya secara implisit ia telah merelakan dirinya menerima dan memikul sebagian tanggung jawab pendidikan yang terpikul di pundak para orang tua. (Zakiah Daradjat, 2001:39) Orang tua tatkala menyerahkan anaknya ke sekolah, berarti sebagian tanggung jawab orang tua sudah menjadi tanggung jawab guru dimana guru harus mendidik siswa sama dengan mendidik anaknya sendiri. Setiap orang tua menginginkan anaknya berilmu pengetahuan, berakhlak sesuai dengan ajaran Islam, berarti guru harus mengarahkan siswa kepada apa yang diinginkan oleh orang tua tersebut.

2) Tugas Guru

Tugas guru adalah membina seluruh kemampuan dan potensi serta sikap yang baik kepada peserta didik sesuai dengan ajaran Islam. Hal ini berarti bahwa perkembangan sikap dan kepribadian tidak terbatas pelaksanaannya melalui pembinaan dalam kelas saja. Dengan kata lain tugas guru dalam pembinaan peserta didik tidak terbatas pada interaksi pembelajaran saja.

Selanjutnya menurut Slameto, tugas seorang guru adalah :

1) Mendidik dengan titik berat memberikan arah dan motivasi pencapaian tujuan, baik jangka pendek maupun jangka panjang

2) Memberikan fasilitas pencapaian tujuan melalui pengalaman belajar yang memadai

3) Membantu perkembangan aspekaspek pribadi, seperti sikap, nilai-nilai dan penyesuaian diri. (Slameto, 1995: 97)

\section{d. Mata Pelajaran Pendidikan Agama Islam}

1) Pengertian Mata Pelajaran Pendidikan Agama Islam

Istilah pendidikan agama Islam dipergunakan dalam mata pelajaran pendidikan Agama Islam yang dilaksanakan pada sekolah-sekolah yang berada di bawah naungan Departemen Pendidikan dan Kebudayaan. (Ramayulis, 2013:4)

Pendidikan agama Islam menekan keseimbangan, keselarasan dan keserasian antar hubungan manusia dengan Allah, dengan sesama 
manusia, dengan diri sendiri dan hubungan dengan alam sekitarnya.

2) Karakteristik Mata Pelajaran Pendidikan Agama Islam

Pengajaran agama Islam diberikan pada sekolah umum dan sekolah agama baik negeri maupun swasta. Pengajaran agama Islam diimplementasikan dalam bentuk mata pelajaran Pendidikan Agama Islam pada sekolah umum dan pada sekolah agama dibagai dalam empat mata pelajaran yaitu akidah akhlak, al-Qur'an hadits, sejarah Islam dan mata pelajaran fikih.

Pada sekolah umum pengajaran agama merupakan satu kesatuan dan dipandang sebagai sebuah mata pelajaran Pendidikan Agam Islam. Sedangkan pada sekolah agama pengajaran agama Islam dibagi menjadi empat mata pelajaran yaitu mata pelajaran akidah akhlak, al-Qur'an hadits, mata pelajaran fikih, dan sejarah Islam. (Zakiah Daradjat, 2001: 262)

3) Tujuan Mata Pelajaran Pendidikan Agama Islam

Zakiah Daradjat mengemukakan bahwa tujuan mata pelajaran pendidikan agama Islam adalah membina manusia beragama berarti manusia yang mampu melaksanakan ajaran-ajaran Islam dengan baik dan sempurna, sehingga tercermin pada sikap dan tindakan dalam seluruh kehidupannya, dalam rangka mencapai kebahagian dan kejayaan hidup dunia dan akhirat. (Zakiah Daradjat, 2001: 172)

\section{PEMBAHASAN}

Hasil penelitian ini akan dideskripsikan berdasarkan temuan tentang Pelaksanaan Pendidikan Agama Islam oleh Guru Sekolah Dasar pada Gurus I Lubuk Sikarah Kota Solok dalam hal penyusunan rencana pembelajaran, pelaksanaan pembelajaran, dan evaluasi hasil belajar. Untuk selanjutnya dianalisis sehingga dapat diperoleh makna yang terkandung dari hasil penelitian ini, analisis tersebut dilakukan sepanjang penelitian dan dilakukan terus menerus dari awal sampai akhir penelitian

\section{Pelaksanaan Pendidikan Agama Islam oleh Guru dalam Menyusun Rencana Pembelajaran}

Berdasarkan hasil wawancara dan observasi yang penulis lakukan terhadap guru pendidikan agama Islam sekolah dasar yang tergabung pada Gugus I Lubuk Sikarah Kota Solok ada melakukan tugas dan perannya sebagai seorang pendidik khususnya dalam pelaksanaan penyusunan rancana pembelajaran.

\section{Pelaksanaan Pendidikan Agama Islam oleh Guru dalam Pelaksanaan Pembelajaran}

Berdasarkan hasil wawancara dan observasi yang penulis lakukan terhadap guru pendidikan agama Islam sekolah dasar yang tergabung pada Gugus I Lubuk Sikarah Kota Solok ada melakukan tugas dan perannya sebagai seorang pendidik khususnya dalam pelaksanaan pembelajaran.

3. Pelaksanaan Pendidikan Agama Islam oleh Guru dalam Evaluasi Hasil Belajar 
Berdasarkan hasil wawancara dan observasi yang penulis lakukan terhadap guru pendidikan agama Islam sekolah dasar yang tergabung pada Gugus I Lubuk Sikarah Kota Solok ada melakukan tugas dan perannya sebagai seorang pendidik khususnya dalam pelaksanaan evaluasi hasil belajar.

\section{PENUTUP}

\section{Kesimpulan}

Berdasarkan hasil pembahasan yang penulis lakukan pada bagian sebelumnya dapat disimpulkan sebagai berikut : Guru mata pelajaran pendidikan agama Islam yang tergabung dalam Gugus I Lubuk Sikarah telah memiliki melaksanakan menyusunan rencana pembelajaran. Dalam hal ini terbukti bahwa berdasarkan hasil wawancara dan observasi yang penulis lakukan terhadap guru mata pelajaran pendidikan agama Islam yang tergabung pada Gugus I Lubuk Sikarah Kota Solok ada melakukan tugas dan perannya sebagai seorang pendidik khusus dalam bidang atau aspek profesionalitas dalam bidang penyusunan rencana pembelajaran.

Guru mata pelajaran pendidikan agama Islam yang tergabung dalam Gugus I Lubuk Sikarah telah melaksanakan pembelajaran. Dalam hal ini terbukti bahwa berdasarkan hasil observasi yang penulis lakukan terhadap guru mata pelajaran pendidikan agama Islam yang tergabung pada Gugus I Lubuk Sikarah Kota Solok ada melakukan tugas dan perannya sebagai seorang pendidik khusus dalam bidang atau aspek profesionalitas dalam bidang pelaksanaan pembelajaran.
Guru mata pelajaran pendidikan agama Islam yang tergabung dalam Gugus I Lubuk Sikarah telah melaksanakan evaluasi pembelajaran hasil belajar. Dalam hal ini terbukti bahwa berdasarkan hasil observasi yang penulis lakukan terhadap guru mata pelajaran pendidikan agama Islam yang tergabung pada Gugus I Lubuk Sikarah Kota Solok ada melakukan tugas dan perannya sebagai seorang pendidik khusus dalam bidang atau aspek profesionalitas dalam bidang evaluasi pembelajaran.

\section{Saran}

Dalam kesempatan ini penulis menyarankan sebagai berikut :

a. Diharapkan kepada Gugus agar dapat menjalankan peranannya dalam memberikan pembinaan dengan sebaikbaiknya kepada guru-guru pendidikan agama Islam.

b. Diharapkan kepada sekolah agar bisa ikut serta dalam memberikan bimbingan dan pembinaan terhadap guru pendidikan agama Islam demi terciptanya kualitas guru pendidikan agama Islam yang semakin baik.

c. Diharapkan kepada pemerintah khususnya yang bergerak dalam bidang pendidikan agar dapat memberikan dukungan baik moril maupun materil demi terwujudnya profesionalitas guru pendidikan agama Islam.

\section{KEPUSTAKAAN ACUAN}

Abdul Gafar dan Irfan dan Muhammad Jamil, Re-Formulasi Rancangan Pembelajaran Pendidikan Agama Islam, Jakarta: Nur Insani, 2003 
Didin Hafidudin dan Hendri Tanjung, Manajemen Syariah dalam Prkatik, Jakarta: Gema Insani, 2003

http://wapikweb.org/article/detail/workshoppenyusunan-rpp-berkarakter-bangsaAA-01130.php, diunduh tanggal 6 Maret 2013 pukul 14.00

Miles dan Huberman, An Expended Source Book: Qualitative Data Analiysis, London: Page Publication, 1984

Nunu Ahmad An-Nahidl.,dkk, Pendidikan Agama di Indonesia: Gagasan dan Realita, Jakarta: Puslitbang Pendidikan Agama dan Keagamaan, 2010

Ramayulis, Profesi \& Etika Keguruan, Jakarta: Kalam Mulia, 2013
-------, Ilmu Pendidikan Islam, Jakarta: Kalam Mulia, 2008

Slameto, Belajar dan Faktor-faktor yang Mempengarubinya, Jakarta: Rineka Cipta, 1995

Undang-undang Nomor 14 Tahun 2005 tentang Guru dan Dosen, Jakarta: Departemen Agama RI., 2006

Zakiah Daradjat, Ilmu Jiwa Agama, Jakarta: Bulan Bintang, 1970

-------, Metodik Khusus Pengajaran Agama Islam, Jakarta: Bumi Aksara, 2001 